\title{
Association between Smartphone Addiction and Body Mass Index amongst Dental Students
}

\author{
Prabhu Subramani ${ }^{1}$, Abishek Mohan ${ }^{2}$
}

\begin{abstract}
Introduction: Smartphones had become inevitable in the present generation and it had made the life to live with ease. However, on the negative side it had brought many people to live in virtual world taking a toll on their physical, mental health and wellbeing. Dental students use smartphones for various reasons like learning, communication, etc., the present study was undertaken to assess the association between smartphone addiction and body mass index (BMI) among dental students.

Materials and methods: A cross-sectional descriptive study employing cluster random sampling was conducted among $n=171$, dental students in Chennai, India. Smartphone addiction scale-short version (SAS-SV) was used to assess smartphone addiction and BMI was assessed by measuring the height and weight of the dental students.

Results: $n=89(52 \%)$ of the study subjects were addicted to smartphone. The male students were more addicted to smartphone than female students. There is a statistically significant association between years of smartphone usage and smartphone addiction. $60.8 \%$ of the study subjects had "Normal" BMI.

Conclusion: Smartphone addiction is significantly higher among dental students affecting $52 \%$ of the study population. There is no significant association between smartphone addiction and BMI amongst dental students.

Keywords: Body mass index, Dental students, Smartphone addiction.

Journal of Oral Health and Community Dentistry (2019): 10.5005/jp-journals-10062-0053
\end{abstract}

\section{INTRODUCTION}

A mobile phone that performs many of the functions of a computer, typically having a touch screen interface, internet access, and an operating system capable of running downloaded apps is called a "Smartphone".1. Smartphone offers a technologically advanced method of social interaction, the risk of becoming obsessed can hinder happiness. Most impressively, smartphone introduced the "World of Apps" where applications can be got for almost anything and everything and thus shift a part of work to electronic devices. In this way gradually and stealthily Smartphone with their allsolutions-at-palm applications and technologies have crept into human world. They have made users so helplessly dependent that one may be at a loss if smartphone vanished.

Smartphone reliance can be said to fall under the umbrella of technology addiction. Such an addiction is present when there is compulsive use of the technology leading to preoccupation, tolerance, unsuccessful efforts to control or stop using, withdrawals, loss of control, significant impairment or neglect in any domain of life, lying to family members about the extent of involvement with the device and using the device as an escape or to relieve low mood. ${ }^{2}$

Smartphone addiction has significant risks and consequences on physical and mental health. ${ }^{3}$ The addiction magnitude ranged from 39 to $44 \%{ }^{4}$ in India. It was found that smartphone addiction was more prevalent in younger adolescents when compared with young adults (19 years and older). ${ }^{5}$ The prevalence of smartphone addiction was quite high among students. ${ }^{6}$ A typical Nomophobe can be identified by some characteristics such as never turning off the phone, obsessively checking missed texts and calls, bringing the phone everywhere, using phones at inappropriate times and missing opportunities for face-to-face interaction while preferring
1,2Department of Public Health Dentistry, Asan Memorial Dental College and Hospital, Chengalpattu, Tamil Nadu, India

Corresponding Author: Prabhu Subramani, Department of Public Health Dentistry, Asan Memorial Dental College and Hospital, Chengalpattu, Tamil Nadu, India, Phone: +91 9080756119, e-mail: prabhu.dent@gmail.com

How to cite this article: Subramani P, Mohan A. Association between Smartphone Addiction and Body Mass Index amongst Dental Students. J Oral Health Comm Dent 2019;13(3):73-76.

Source of support: Nil

Conflict of interest: None

over the phone contact. In some severe cases, people may also face physical side effects such as panic attacks, shortness of breath, trembling, sweating, accelerated heart rate, pain in the hand joints, neck and back pain, etc. ${ }^{2}$

Due to the increase in smart phone usage among the students, there is a lack in physical activity among them and there is also increase in "Junk Food" snacking habits among the students. Physical inactivity has partnered unhealthy diet as the socioeconomic transition renders only $14 \%$ of the population in India involved in regular nonoccupational physical activity. ${ }^{7}$

Smartphone usage is a common phenomenon among dental students and they use smartphone commonly for the following purposes: (1) communication, (2) learning, (3) research purpose, (4) E-shopping, (5) gaming and (6) watching videos. Smartphone usage among dental students has been documented in the study by Saheer et al., ${ }^{8}$ where a significant number of students were addicted to smartphone and lack of physical activity is one of the outcomes of smartphone addiction. Hence the present study was undertaken

(c) The Author(s). 2019Open Access This article is distributed under the terms of the Creative Commons Attribution 4.0 International License (https://creativecommons. org/licenses/by-nc/4.0/), which permits unrestricted use, distribution, and non-commercial reproduction in any medium, provided you give appropriate credit to the original author(s) and the source, provide a link to the Creative Commons license, and indicate if changes were made. The Creative Commons Public Domain Dedication waiver (http://creativecommons.org/publicdomain/zero/1.0/) applies to the data made available in this article, unless otherwise stated. 


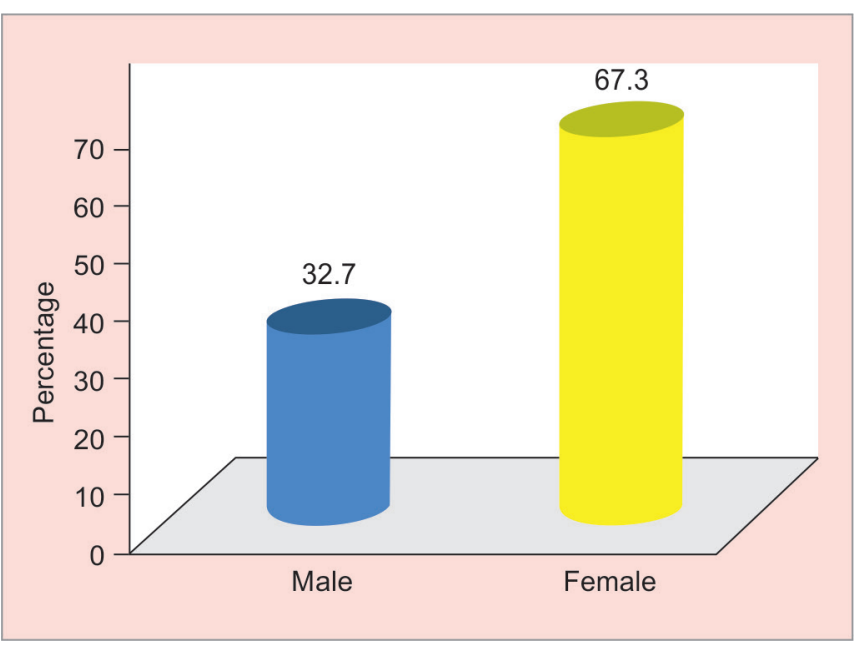

Fig. 1: Distribution of study subjects according to gender

to assess the association between smartphone addiction and BMI among dental students.

\section{Materials and Methods}

A cross-sectional descriptive study employing cluster random sampling was conducted among dental students in Chennai. Sample size for the study was estimated to be $n=151$, undergraduate dental students (90\%-power and 95\% - confidence interval] based on the prevalence of smart phone addiction among dental students in the study conducted by Saheer et al., ${ }^{8}$ using Openepi statistical software. Prior to the start of the study approval has been obtained from the Institutional Scientific Review Committee, Asan Memorial Dental College and Hospital and concerned college authorities.

Undergraduate dental students who are using smartphone were included in the study, dental students who are using feature phone, dental students who were under psychotherapy were excluded from the study. Survey instrument consists of a self-administered pretested, validated questionnaire to assess smart phone addiction using SAS-SV developed by Kwon et al., ${ }^{9}$ followed by clinical examination to record height using a stature meter manufactured by Medlife India Private Limited, New Delhi in centimeters $(\mathrm{cm})$ and weight using TALGO Digital Glass Weighing Scale, NR Enterprises, India in kilogram (kg).

SPSS Version 23 was used for statistical analysis, Shapiro-Wilk test was used to test for normalcy of the distribution and Chi-square test for association.

\section{Results}

A cross-sectional descriptive study was conducted among undergraduate dental students to assess the association between their smart phone usage and BMI. Shapiro-Wilk test for normalcy showed that the data follows a non-Gaussian distribution, hence nonparametric test for association, Chi-squared test for association are performed. Figure 1 depicts the distribution of study subjects according to gender. Among the $n=171$, study subjects, $n=56$ (32.7\%) were male and $n=115$ (67.3\%) were female.

Figure 2 depicts the distribution of study subjects according years of smart phone usage. Among the $n=171$ study subjects, $n=35(20.5 \%)$ were using smart phone for $<3$ years, $n=89(52 \%)$

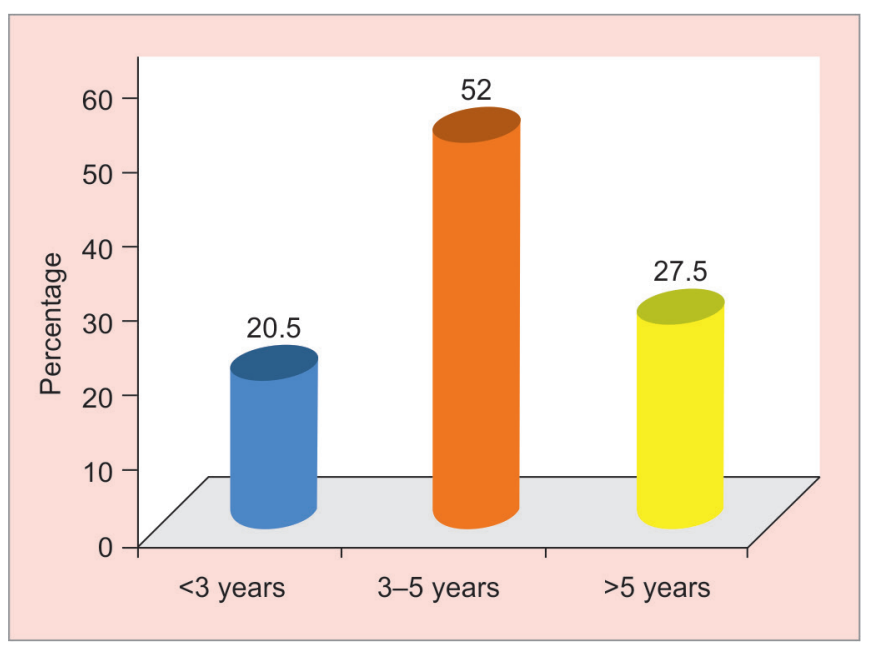

Fig. 2: Distribution of study subjects according to years of smart phone usage

were using smart phone for $3-5$ years and $n=47$ (27.5\%) were using smart phone for $>5$ years.

Table 1 depicts the comparison of SAS-SV score across gender, the cutoff value for addiction as given by Kwon et al., ${ }^{9}$ was $>31$ for male and $>33$ for female study subjects. Among the $n=171$ study subjects, $n=82$ (48\%) were not addicted to smart phone and $n=89$ (52\%) were addicted to smartphone. Prevalence of smart phone addiction was more among male $n=34$ (60.7\%) compared to female $n=55$ (47.8\%), however the difference in smartphone addiction was not significant across gender.

Table 2 depicts the comparison of years of smart phone usage and addiction level. Among the study subjects, $n=57$ (33.4\%) of the study subjects using mobile phone for a period of 3-5 years were more addicted and the addiction level and years of smartphone usage was statistically significant.

Table 3 depicts the response of the study subjects to the smart phone addiction scale-short version, $n=50$ (29.2\%) of the study subjects agreed to missing planned work due to smart phone use, $n=43(25.1 \%)$ of the study subjects reported that they feel impatient when they are not holding a smart phone, $n=61$ (35.7\%) of the study subjects reported that they constantly check smart phone so as not to miss conversations between other people on Twitter or Facebook, $n$ $=58(33.9 \%)$ study subjects reported that they use their smart phone longer than they intended and only $n=70(40.9 \%)$ disagreed to the fact that having smart phone in my mind even when l am not using it.

Table 4 depicts the distribution of study subjects according to BMI score and gender, $n=39(69.6 \%)$ male study subjects had normal BMI and $n=65$ (56.5\%) female study subjects had normal BMI, $n=29$ (25.2\%) female study subjects were overweight and there is no significant difference in BMI score across gender.

Table 5 depicts the association between SAS-SV score and BMI across study subjects, Chi-square test for association showed that there is no significant association between the smartphone addiction scale score and BMI among the study subjects.

\section{Discussion}

Smartphone had become the sixth finger for the present generation, possessing a smartphone is perceived to be essential among the students and young adults. Present study was undertaken to assess the association between smartphone addiction and BMI among 
Table 1: Comparison of SAS-SV score across gender

\begin{tabular}{|c|c|c|c|c|c|c|}
\hline SAS score & Addiction-Yes*, n (\%) & Addiction-No*, $n(\%)$ & Total, $n$ (\%) & Chi-square value & $D f$ & $p$ value \\
\hline Male* $($ Yes, $>31)$ & $34(60.7)$ & $22(39.3)$ & $56(100)$ & 2.017 & 1 & 0.15 \\
\hline Female* $^{*}$ Yes, >33) & $55(47.8)$ & $60(52.2)$ & $115(100)$ & & & \\
\hline
\end{tabular}

${ }^{*}$ Chi-square test, $(p>0.05$-not significant)

Table 2: Comparison of years of smart phone usage and smartphone addiction scale-short version score among the study subjects

\begin{tabular}{|c|c|c|c|c|c|}
\hline Years of usage* & Addiction-Yes*, n (\%) & Addiction-No*,$n(\%)$ & Chi-square value & Df & $p$ value \\
\hline$<3$ & $7(4)$ & $28(16.4)$ & 19.6 & 2 & 0.00 \\
\hline $3-5$ & $57(33.4)$ & $32(18.8)$ & & & \\
\hline$>5$ & $25(14.6)$ & $22(12.8)$ & & & \\
\hline Total & $89(52)$ & $82(48)$ & & & \\
\hline
\end{tabular}

${ }^{*}$ Chi-square test, $(p<0.05$-highly significant $)$

Table 3: Smart phone addiction scale-short version response among the study subjects

\begin{tabular}{|c|c|c|c|c|c|c|c|}
\hline S. no. & Question & $\begin{array}{l}\text { Strongly } \\
\text { disagree (\%) }\end{array}$ & Disagree (\%) & $\begin{array}{l}\text { Weakly } \\
\text { disagree (\%) }\end{array}$ & Weakly agree (\%) & Agree (\%) & $\begin{array}{l}\text { Strongly } \\
\text { agree (\%) }\end{array}$ \\
\hline 1 & $\begin{array}{l}\text { Missing planned work due to smart } \\
\text { phone use }\end{array}$ & $38(22.2)$ & $23(13.5)$ & $26(15.2)$ & $20(11.7)$ & $14(8.2)$ & $50(29.2)$ \\
\hline 2 & $\begin{array}{l}\text { Having a hard time concentrating in } \\
\text { class, while doing assignments, or } \\
\text { while working due to smart phone } \\
\text { use }\end{array}$ & $60(35.1)$ & $30(17.5)$ & $24(14)$ & $16(9.4)$ & $15(8.8)$ & $26(15.2)$ \\
\hline 3 & $\begin{array}{l}\text { Feeling pain in the wrists or at the } \\
\text { back of the neck while using a smart } \\
\text { phone }\end{array}$ & $54(31.6)$ & $22(12.9)$ & $23(13.5)$ & $21(12.3)$ & $13(7.6)$ & $38(22.2)$ \\
\hline 4 & $\begin{array}{l}\text { Would not be able to stand not having } \\
\text { a smart phone }\end{array}$ & $55(32.2)$ & $31(18.1)$ & $22(12.9)$ & $11(6.4)$ & $13(7.6)$ & $39(22.8)$ \\
\hline 5 & $\begin{array}{l}\text { Feeling impatient and irritated when } \\
\text { I am not holding my smart phone }\end{array}$ & $53(31)$ & $30(17.5)$ & $19(11.1)$ & $13(7.6)$ & $13(7.6)$ & $43(25.1)$ \\
\hline 6 & $\begin{array}{l}\text { Having my smart phone in my mind } \\
\text { even when I am not using it }\end{array}$ & $70(40.9)$ & $23(13.5)$ & $17(9.9)$ & $26(15.2)$ & $10(5.8)$ & 25 (14.6) \\
\hline 7 & $\begin{array}{l}\text { I will never give up using my smart } \\
\text { phone even when my daily life is } \\
\text { already greatly affected by it }\end{array}$ & $57(33.3)$ & $28(16.4)$ & $21(12.3)$ & $10(5.8)$ & $20(11.7)$ & $35(20.5)$ \\
\hline 8 & $\begin{array}{l}\text { Constantly checking my smart phone } \\
\text { so as not miss conversations between } \\
\text { other people on Twitter or Facebook }\end{array}$ & $37(21.6)$ & $27(15.8)$ & $22(12.9)$ & $14(8.2)$ & $10(5.8)$ & $61(35.7)$ \\
\hline 9 & $\begin{array}{l}\text { Using my smart phone longer than I } \\
\text { had intended }\end{array}$ & $27(15.8)$ & $18(10.5)$ & $20(11.7)$ & $29(17)$ & $19(11.1)$ & $58(33.9)$ \\
\hline 10 & $\begin{array}{l}\text { The people around me tell me that } \\
\text { I use my smart phone too much }\end{array}$ & $31(18.1)$ & $27(15.8)$ & $27(15.8)$ & $29(17)$ & $10(5.8)$ & $47(27.5)$ \\
\hline
\end{tabular}

Table 4: Distribution of study subjects according to body mass index score across gender

\begin{tabular}{|c|c|c|c|c|c|c|c|}
\hline Gender $^{*}$ & Underweight ${ }^{*}, n$ (\%) & Normal $^{*}, n(\%)$ & Overweight ${ }^{*}, n(\%)$ & Obese*, $n(\%)$ & Chi-square value & $D f$ & $p$ value \\
\hline Male & $7(12.5)$ & $39(69.6)$ & $8(14.3)$ & $2(3.6)$ & 3.602 & 3 & 0.30 \\
\hline Female & $14(12.2)$ & $65(56.5)$ & $29(25.2)$ & $7(6.1)$ & & & \\
\hline Total & $21(12.2)$ & $104(60.8)$ & $37(21.7)$ & $9(5.3)$ & & & \\
\hline
\end{tabular}

${ }^{*}$ Chi-square test, $(p>0.05$-not significant)

Table 5: Association between smartphone addiction scale-short version and body mass index among the study subjects

\begin{tabular}{|c|c|c|c|c|c|c|c|c|}
\hline $\begin{array}{l}\text { Smart phone } \\
\text { addiction* }\end{array}$ & Underweight ${ }^{*}, n(\%)$ & Normal $^{*}, n(\%)$ & Overweight ${ }^{*}, n(\%)$ & Obese $^{*}, n(\%)$ & Total $^{*}, n(\%)$ & $\begin{array}{l}\text { Chi-square } \\
\text { value }\end{array}$ & Df & $p$ value \\
\hline No & $13(15.8)$ & $45(54.8)$ & $21(25.6)$ & $3(3.6)$ & $82(100)$ & 4.47 & 3 & 0.215 \\
\hline Yes & $8(9)$ & $59(66.3)$ & $16(18)$ & $6(6.8)$ & $89(100)$ & & & \\
\hline
\end{tabular}

${ }^{*}$ Chi-square test, $(p>0.05$-not significant $)$ 
dental students. Based on the cutoff value for SAS-SV by Kwon et al., ${ }^{9}$ in the present study $52 \%$ of the students were addicted to smartphone, higher than the study conducted by Davey et al. ${ }^{4}$ where it was $44 \%$, this could be attributed to the sudden transition in the Indian Telecom Industry and mobile data usage plans which drastically changed at the end of 2016 leading to the overall increase in mobile data usage. ${ }^{10}$ Also some the college students participated in our study were provided with free Wi-Fi services in their campus.

Gender comparison showed that $60.7 \%$ males were addicted to smart phone and only $47.8 \%$ females were addicted to smart phone, the results are similar to the study conducted by Saheer et al., ${ }^{8}$ Bisen et al. ${ }^{11}$ and Ammati et al. ${ }^{12}$ Mobile addiction among male students is more among the study population and this could be attributed to the habit of playing games among male students compared to female students. In the present study "Constantly checking my smart phone so as not miss conversations with people on Twitter or Facebook" 35.7\% of the study subjects "Strongly agree" to the statement, this was higher than the study conducted by Saheer et al. ${ }^{8}$ where only $10.1 \%$ of the study subjects responded "Strongly agree" to the statement. This shows that the study participants were also addicted to social networks.

Assessment of BMI among the study subjects showed that the proportion of underweight, normal, overweight and obesity were $12.2 \%, 60.8 \%, 21.7 \%$ and $5.3 \%$ respectively. The number of students with normal BMI was higher in the present study compared to the study conducted by Radhika et al. ${ }^{13}$ where only $32.9 \%$ of the study subjects had normal BMI.

There is no significant association between the SAS-SV and $\mathrm{BMI}$ among the study population due to the fact that most of the study participants in the study were on a standard diet and snacking habit is rare among the students, the present study did not assess the other factors responsible for altering BMI like dietary habits, physical activity, systemic diseases etc.

Majority of the students are addicted to smartphone in the present study, further studies are needed to explore the impact of smartphone on physical, mental health and its impact on the quality of life and academic performance of the students.

\section{CONCLUSION}

Smartphone is inevitable for the current generation like food, water and shelter. Students have to be cautious in using this device as the results of the present study concluded that significant numbers of students are addicted to smartphone. Although there is no significant impact of smartphone addiction on BMI, continuous usage of smartphone among dental students may have physical health impaired.

\section{References}

1. Smart Phone Definition accessed from https://en.oxforddictionaries. com/definition/smartphone on 01.05.2019.

2. Kanmani A, Bhavani U, Maragatham R. NOMOPHOBIA - an insight into its psychological aspects in India. Int J Indian Psychol 2017;4(2):5-15. ISSN:2348-5396 (e), ISSN:2349-3429 (p), DIP:18.01. 041/20170402, ISBN:978-1-365-71287-6.

3. Kuss DJ, Griffiths MD, Karila L, et al. Internet addiction: a systematic review of epidemiological research for the last decade. Curr Pharm Des 2014;20(25):4026-4052. DOI: 10.2174/13816128113199990617.

4. Davey S, Davey A. Assessment of smartphone addiction in indian adolescents: a mixed method study by systematic review and metaanalysis approach. Int J Prev Med 2014;5(12):1500-1511.

5. Haug S, Castro RP, Kwon M, et al. Smartphone use and smartphone addiction among young people in Switzerland. J Behav Addict 2015;4(4):299-307. DOI: 10.1556/2006.4.2015.037.

6. De-Sola Gutiérrez J, Rodriguez de Fonseca F, Rubio G. Cellphone addiction: a review. Front Psychiatry 2016;7:175.

7. Rastogi T, Vaz M, Spiegelman $D$, et al. Physical activity and risk of coronary heart disease in india. Int J Epidemiol 2004;33(4):759-767. DOI: 10.1093/ije/dyh042.

8. Saheer A, Shalik M, Roy H, et al. Nomophobia: a cross-sectional study to assess mobile phone usage among Al Azhar dental students, Kerala. Int J Dev Res 2018;8(06):20825-20828.

9. Kwon M, Kim D-J, Cho H, et al. The smartphone addiction scale: development and validation of a short version for adolescents. PLoS ONE 2013;8(12):e83558. DOI: 10.1371/journal.pone.0083558.

10. Telecom Subscription Reports, accessed from https://main.trai.gov. in/release-publication/reports/telecom-subscriptions-reports. on 01.05.2019.

11. Bisen S, Deshpande Y. An analytical study of smartphone addiction among engineering students: a gender differences. Int J Indian Psychol 2016;4(1):70-81. DOI: 10.25215/0401.128.

12. Ammati R, Kakunje A, Karkal R, et al. Smartphone addiction among students of medical university in south india: a cross-sectional study. Ann Int Med Den Res 2018;4(2):PY01-PY04. DOI: 10.21276/ aimdr.2018.4.2.PY1.

13. Radhika B, Vrushabhendra HN, Surendar R, et al. Association of diet and physical activity with BMI among dental students in Puducherry. Int J Community Med Public Health 2018;5:3410-3412. DOI: 10.18203/2394-6040.ijcmph20183071. 